\title{
Critical pathways to enhanced innovation diffusion and business performance in Australian design firms
}

\author{
Kriengsak Panuwatwanich \\ Griffith School of Engineering, Griffith University \\ Gold Coast Campus, Queensland 4222, Australia \\ Contact email: k.panuwatwanich@griffith.edu.au
}

\author{
Rodney A. Stewart \\ Griffith School of Engineering, Griffith University \\ Gold Coast Campus, Queensland 4222, Australia \\ Contact email: r.stewart@griffith.edu.au
}

Sherif Mohamed

Griffith School of Engineering, Griffith University

Gold Coast Campus, Queensland 4222, Australia

Contact email: $\underline{\text { s.mohamed@griffith.edu.au }}$

\section{Citation Details:}

Panuwatwanich, K., Stewart, R.A., Mohamed, S. (2009) "Critical pathways to enhanced innovation diffusion and business performance in Australian design firms", Automation in Construction, Vol. 18 No. 6, pp. 790-797. 


\title{
Critical pathways to enhanced innovation diffusion and business performance in Australian design firms
}

\begin{abstract}
This paper presents a study that extends on previous empirical research, which examined the role of enabling 'climate for innovation' constructs in determining the level of innovation diffusion outcomes, and subsequent business performance in architectural and engineering design (AED) firms. Whilst this previous study elucidated the relationships between broad theoretical constructs, the present study was focused on targeting the significant enabling factor interrelationships with the core outcomes that result from the innovation diffusion process. To achieve this objective, a sequential mixed-method research design combining quantitative and qualitative analysis techniques was employed. The quantitative techniques included a correlation analysis to identify the strong factor relationships, followed by Structural Equation Modelling (SEM) to determine the critical pathways for enhancing innovation diffusion and ultimately heightened levels of client satisfaction. Following path model extraction, qualitative interviews with five Australian AED firms were conducted. The interview findings confirmed the uncovered significant pathways, and provided in-depth insights into how the improvement of critical enabling factors could leverage improved innovation diffusion outcomes and business performance.
\end{abstract}

Keywords: Architectural and engineering design, Australia, innovation diffusion, path analysis, structural equation modelling

\section{Introduction}

It is widely accepted that innovation plays an important role in determining the competitiveness among firms operating in the construction industry. Specifically, as design is a critical element in construction, innovation is highly vital in the architectural and engineering design (AED) sector where firms are more likely to remain competitive if they are continually successful at developing and/or implementing innovation. To achieve this, it is imperative that firms be able to understand how innovation can be effectively diffused. According to Rogers [1], diffusion is a process in which an innovation is 
communicated among members of a social system over time. Innovation itself has also been regarded as a product of complex social interactions among members of a social system [2,3], within which the generation and/or implementation of such innovation create a social change [4]. As such, successful innovation and its diffusion process have been viewed as dependent chiefly upon socio-psychological processes embedded in the social system [5,6]. In particular, there has been a growing research interest in the 'climate for innovation', a manifestation of socio-psychological phenomena that acts as a critical determinant of people's motivation and behaviour, driving the diffusion process [3,7-9].

Within the construction and built environment research arena, the study of innovation has been perceived as being at the nascent stage [10]. Although many research studies conducted in the past have provided a great deal of knowledge regarding the critical factors and variables that influence the level of innovation within construction organisations, there has been a call for more studies from a social perspective to provide more practical ways of managing, and learning how to manage, innovation within this particular context [11,12]. In response to this, several research studies have been attempted to investigate the extent to which such socio-psychological factors as organisational culture, leadership, etc. influence the implementation and diffusion of innovation. For example, a study of technology adoption decisions with eight construction organisations by Mitropoulos and Tatum [13] highlights a number of factors affecting the adoption of innovation, including: how the company's culture values innovation; management's attitudes towards new technology; the ability of management to identify opportunities to improve existing practices; the budget available; and the support by management. In Stewart et al.'s [14] study of information technology (IT) implementation in the Australian construction industry, six organisational barriers to IT innovation were identified: limited resources; lack of perceived return on investment on IT expenditure; lack of organisational strategic planning; reluctance by management to invest in innovation; conservative business practices; and resistance to change by staff. Similarly, Peansupap and Walker [15], in their recent study of IT diffusion and adoption within Australian construction organisations, revealed a number of diffusion factors, such as supportive individual/personal characteristics, open discussion environment, and supervisor and organisational support. None of these studies, however, focus on an 
empirical investigation of the cause-and-effect relationships between climate for innovation and levels of innovation diffusion outcomes within the AED firm context.

To overcome this existing research gap and to advance current knowledge on innovation, the authors recently carried out a study that identified the key socio-psychological constructs underlying the climate for innovation, and revealed through an empirical model, how these constructs impact upon innovation diffusion outcomes and business performance in AED firms [16]. In an effort to achieve greater knowledge on the significant factor links of the developed model, the current paper presents an extended, more in-depth, study aiming to determine the most critical factors within each climate construct, and to investigate how these factors leverage specific innovation-related outcomes. The paper is structured as follows. In the next section, the empirical model developed in the prior study is briefly introduced and discussed. The research method and analytical techniques undertaken in the current study are then described, and the results presented. The final sections provide the discussion and conclusion of the study findings, and recommend possible future research directions.

\section{Research model}

In an attempt to provide a better understanding of the innovation diffusion phenomena from a social perspective, a study was recently conducted by the authors to empirically investigate the impact of the socio-psychological process of innovation diffusion on business performance within the AED firm context [16]. The study was carried out through an assessment of a conceptual model developed from an extensive literature review. As the traditional Diffusion of Innovation (DOI) Theory [1] does not entirely capture the relationships among different levels of social systems and key players within an organisation, other well-established theories relevant to team climate, leadership and organisational culture, were examined and integrated to better address the diffusion process $[17,18]$. This yielded the conceptual model which consisted of three 'climate for innovation' constructs, namely, leadership for innovation (LFI), team climate for innovation (TCI), and organisational culture for innovation (OCI), along with two outcome-orientated constructs addressing innovation diffusion outcomes (IDO) and business performance (BPM). The study employed a quantitative research approach which involved conducting a 
series of multivariate statistical analyses, including Exploratory Factor Analysis (EFA) and Structural Equation Modelling (SEM), based on the data obtained from a questionnaire survey of 181 design professionals representing 57 Australian AED firms. This group of survey respondents accounts for 34.8 percent of 520 design professionals from 300 AED firms, randomly drawn from the Dun and Bradstreet's Australian Business Who is Who Database. EFA using principal component analysis with VARIMAX orthogonal rotation method was undertaken to identify the factors representing each model construct (factor structures). SEM was then performed to assess and refine the conceptual model. Fig. 1 illustrates the final empirical model derived from these analyses. Presented in the model are the causal relationships between the five model constructs derived from the SEM analysis, and the EFA-extracted factors representing each of the constructs (15 factors in total). Further details of these 15 model factors are presented in Table 1. Readers are referred to Panuwatwanich et al. [16] for the complete details of model development and assessment.

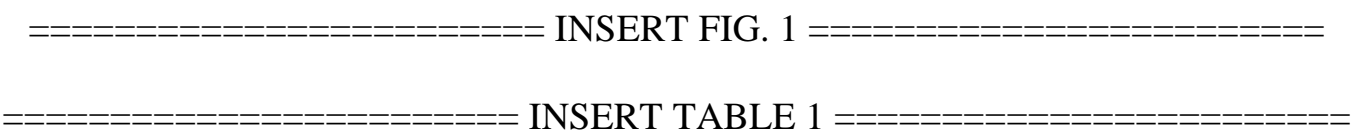

According to Fig. 1, the model shows that the LFI construct strongly and positively influences the TCI construct $(0.72, p<0.001)$. Both constructs also have a positive influence on the OCI construct, with the LFI construct $(0.52, p<0.001)$ having a relatively stronger influence than the TCI construct $(0.35, p<$ 0.01). The OCI construct, in turn, strongly and positively influences the IDO construct $(0.93, p<0.001)$. Finally, the BPM construct was found to be strongly influenced by the IDO construct $(0.77, p<0.001)$. Overall, the model implies that an increase in the level of leadership for innovation will lead to an improved level of both team climate and organisational culture for innovation. Moreover, an improvement in the organisational culture for innovation will, in turn, result in an increased level of innovation diffusion outcomes. Finally, with improved outcomes from the innovation diffusion process, the firm's business performance can be enhanced. The model also highlights the importance of developing conducive leadership for innovation in AED firms, as all the pathways that lead to improved innovation diffusion outcomes and business performance emerged from the LFI construct. 
Evidently, the empirical model revealed valuable insights into the causal relationships between the key climate constructs, and proffered a number of strategic implications for AED firms seeking to enhance their business performance through innovation. However, the model has a limitation in that all factors were treated as indicators representing latent constructs. In other words, the model portrays only relationships between broad organisational perspectives (model constructs), thus offering no information as to which specific activities (model factors) should receive higher priority, in terms of improvement and monitoring, to achieve improved outcomes. In order to enhance the explanatory power of the model, a further study was required to evaluate the interrelationships between the existing constructs at the factor level and, ultimately, to develop and confirm pathways that explain the relationships among critical factors underpinning the empirical model.

\section{Research method}

To achieve the above-mentioned objective, the present study employed both quantitative and qualitative research approaches. Such a hybrid research design has been strongly encouraged in construction management research $[19,20]$. The quantitative approach utilises a series of statistical techniques including correlation and path analyses, which were performed on the data gathered from the questionnaire survey of Australian design professionals $(n=181)$ conducted during 2007 as part of the prior study. The previously developed empirical model presented above (Fig. 1) was treated as a research model for the present study. Specifically, the associations between the factors within the independent and dependent constructs of the model were examined using correlation analysis to unearth the strong and statistically significant relationships. Factors associated with the identified relationships were then isolated and modelled using path analysis to ascertain their potential causal relationships, as suggested in the research model. The constructed path model was then assessed and refined using the SEM technique to produce a final model that portrayed the confirmed causal relationships between such factors.

Following the quantitative analysis, a qualitative study was conducted to ascertain the wider applicability of the path model. This strategy was grounded in the sequential mixed-method research design, whereby a quantitative study was conducted first, and the results obtained were then explained using a qualitative 
research method [21]. For the purpose of this study, semi-structured interviews were undertaken to provide better insights into the phenomenon under investigation. In summary, the research method undertaken in this study consisted of three sequential stages: (1) correlation analysis; (2) path analysis; and (3) interviews with design professionals. Further details for each of these analysis stages are presented in the following sections, along with their associated results.

\section{Quantitative analysis and results}

\subsection{Correlation analysis}

Given that causal relationships between the constructs were previously identified and confirmed in the research model presented above (Fig. 1), Pearson's correlation analysis was performed to identify the strong and statistically significant relationships between the factors within the independent and dependent constructs. In doing so, a correlation matrix was first generated for the entire set of factors using SPSS version 15.0. The matrix was then examined to uncover statistically significant correlations $(p<0.05)$ between factors within the relevant constructs portrayed in the research model. It should be noted that a one-tailed test was used, to provide a stricter measure for establishing statistical significance of correlation coefficients, since the direction of the relationships between the factors were already determined a priori as demonstrated by causal links between the constructs established in the research model. To identify the strong relationships, the strength of these significant correlations was then assessed. To achieve this, the current analysis employed Cohen's [22] effect size classification for correlation coefficients to serve as the criteria upon which to judge the strength of associations between the factors. These classifications are: small $(0.10-0.29)$; medium $(0.30-0.49)$; and large $(\geq 0.50)$. On this basis, only the correlation coefficients greater than or close to 0.50 (i.e. large effect size) were considered to represent 'strong' relationships between the factors. Accordingly, the factors corresponding with these relationships were regarded as 'critical' and were thus included in the subsequent path analysis.

Table 2 shows a matrix containing Pearson's correlation coefficients, which represent the associations between the independent and dependent factors that correspond with the causal relationships between the 
constructs depicted in the research model (Fig. 1). In total, 10 factors associated with large correlation coefficients were identified, as highlighted in the table. These include:

- All three factors from the LFI construct, namely, innovation championing (LFI1), creativity stimulation and inspiration (LFI2), and engagement and support (LFI3);

- Two factors from the TCI construct, namely, participative safety (TCI2) and support for innovation (TCI4);

- Two factors from the OCI construct, namely, propensity for creativity (OCI1) and innovation support and facilitation (OCI3);

- Two factors from the IDO construct, namely, innovative design solutions (IDO1) and innovative design practices (IDO2); and

- One factor from the BPM construct being client satisfaction (BPM2).

Indeed, the above factors were deemed critical as they represent a strongly interrelated set of attributes that underpin the relationships between the constructs in the research model. In order to ascertain the relationships between these factors in a cause-and-effect manner, statistical modelling using the path analysis technique was conducted. The details and results of this analysis are presented in the following section.

INSERT TABLE 2

\subsection{Path analysis}

Following the correlation analysis, path analysis was performed to assess and refine causal relationships between the critical factors identified in the preceding section. The expected outcome of this analysis was a path model that portrays a more definitive process for enhancing innovation diffusion and business performance, in addition to the broad mechanism shown in the research model. Generally, path analysis can be carried out using either multiple regression or SEM techniques [23]. SEM has an advantage over regression since it provides a method for dealing with multiple relationships simultaneously and permits 
the use of non-experimental data for the examination of causal relationships [24]. The analysis began by specifying the initial path model based on the identified 10 highly correlated factors and the relationships shown in the research model. The fit between this initial path model and the survey data was then assessed based on five model fit indices, namely: normed chi-square $\left(\chi^{2} / d f\right)$; goodness-of-fit index (GFI); comparative-fit index (CFI); incremental-fit index (IFI); and root mean square error of approximation (RMSEA). To be considered as having a good model fit, all the indices were measured against the following criteria: $\chi^{2} / d f<3.00$; GFI, CFI, and IFI $>0.90$; and RMSEA $<0.08$ [25]. The assessment was carried out using the AMOS 7.0 program utilising the maximum likelihood method for parameter estimation. The initial results indicated that the path model did not fit the data well. To improve the model fit, a refinement procedure was carried out, which mainly involved removing non-significant paths (i.e. $p$ value greater than 0.05 ) from the model. This led to the elimination of TCI2 since all of the links associated with this factor were not significant. The refinement process yielded the final path model (Fig. 2) that demonstrated an acceptable level of fit, having the following indices: $\chi^{2}=39.42 ; d f=17 ; \chi^{2} / d f=$ $2.32 ; \mathrm{GFI}=0.96 ; \mathrm{CFI}=0.97 ; \mathrm{IFI}=0.97 ;$ and $\mathrm{RMSEA}=0.08$.

As illustrated in Fig. 2, six out of 14 links in the path model have a 'meaningful' standardised coefficient, being greater than or close to 0.30 [26]. Therefore, these links were highlighted to form critical paths, which serve as a focal point for the model interpretation. Firstly, these paths suggest that an increase in the level of leaders' creativity stimulation and inspiration (LFI2) will improve the level of support for innovation in teams (TCI4) as indicated by its standardised path coefficient $(0.34, p<0.01)$. Teams with a high level of innovation support will then contribute significantly to an increase in both the level of a firm's propensity for creativity (OCI1: $0.39, p<0.001$ ) and the level of innovation support and facilitation provided by the firm (OCI3: $0.37, p<0.001)$. Subsequently, achieving a higher level of propensity for creativity will lead to an improved level of innovative design solutions (IDO1: $0.50, p<$ 0.001), whereas the increased level of a firm's support and facilitation will contribute to better innovative 
design practices (IDO2: $0.40, p<0.001$ ). Together, both of these innovation diffusion outcome orientated factors will ultimately lead to enhanced business performance in terms of an improved level of client satisfaction (BPM2), with $\operatorname{IDO} 2(0.34, p<0.001)$ having a slightly greater influence than IDO1 $(0.28, p<$ 0.001). In order to assess the degree of relevance of the path model under real-work settings, and to gain deeper insights into the relationships within the model, qualitative interviews were conducted. The key outcomes of the interview and associated discussion on how they support, or otherwise, the path model is presented in the following section.

\section{Qualitative analysis and results}

During the first quarter of 2008, interviews were conducted with design professionals employed by Australian AED firms. Specifically, semi-structured interviews were used to maximise the flexibility of the interview, and to allow it to be tailored to suit the individual [27]. Face-to-face interviews were chosen to provide the opportunity for clarifying ambiguous questions, as well as to observe the actual environment of the firm being studied. During each interview session, an interview guide was used to maintain the direction of the conversation and the relevant lines of enquiry whilst probing into the issues of interest. For the purpose of time and cost efficiency, the sampling frame was constrained to firms that had offices in the cities of Brisbane or the Gold Coast, Australia, which the authors were based. The sample drawn from this domain was considered adequate since these two cities were major AED markets in Australia, in which various local, national and international AED firms operate. Based on a convenient sampling technique, 15 firms were contacted for interviews. Of these, five firms agreed to participate in this part of the study, representing a 33.3 percent response rate. In total, 19 design professionals, comprising five managerial (26.3\%), six senior (31.6\%) and eight junior (42.1\%) staff members from these firms were interviewed. To maintain their anonymity, personal details of the interviewees are not presented, and the five firms are referred to as firms A, B, C, D and E. The profiles of the interview participants are summarised in Table 3.

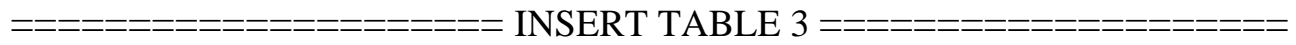


Overall, the interview participants comprised a good mix of design professions employed by firms of different types. As Table 3 shows, the size of the firms, in terms of the number of employees, ranged from 100-360 employees. Firms A and B provided engineering consultancy, whereas firms C, D and E provided architectural design, as their main services. The scope of operation of these firms ranged from regional to international, with multiple offices. The 19 design professionals comprised four design team members from each of the firms $\mathrm{A}, \mathrm{B}, \mathrm{C}$ and $\mathrm{D}$, and three members from firm $\mathrm{E}$. The break down of professional position was five engineers (26.3\%), nine architects (47.4\%), and five draftspersons/ architectural technicians $(26.3 \%)$. The duration of each interview ranged from 20 to 60 minutes, with an average of 40 minutes. Four sets of interviews were conducted in Brisbane, and one was conducted in the Gold Coast. All interviews were carried out by the first author of this paper on a one-to-one basis. To obtain accurate descriptions of the interviewee's responses and comments, all interviews were recorded and transcribed. Following this, The interview transcripts were coded using a descriptive coding technique [28], which helped facilitate the classification of transcripts' content into relevant model factors. These coded transcripts were then analysed, in relation to the developed path model (Fig. 2). The qualitative results obtained from the interviews analysis are presented below, with respect to each of the following four path relationships highlighted in the path model:

- Path relationship 1 - Stimulating and inspiring creativity as the key to improved team support for innovation (LFI2 $\rightarrow$ TCI4);

- Path relationship 2 - Influence of team support for innovation on a firm's culture for innovation (TCI4 $\rightarrow \mathrm{OCI} 1$ and $\mathrm{TCI} 4 \rightarrow \mathrm{OCI} 3)$

- Path relationship 3 - Influence of innovation-conducive culture on innovative design practices and solutions $(\mathrm{OCI} 1 \rightarrow \mathrm{IDO} 1$ and $\mathrm{OCI} 3 \rightarrow \mathrm{IDO} 2)$; and

- Path relationship 4 - Achieving client satisfaction through improved innovation diffusion outcomes $(\mathrm{IDO} 1 \rightarrow \mathrm{BPM} 2$ and IDO2 $\rightarrow$ BPM2). 


\subsection{Path relationship 1}

Essentially, leaders can inspire and stimulate creativities among team members by encouraging and challenging them to develop their own ideas, and show recognition and appreciation for their creativity. These behaviours, according to the path model (LFI2 $\rightarrow$ TCI4), will increase the level of team support for innovation as team members will actively search for new ideas and cooperate to experiment with and further develop such ideas. This relationship was corroborated by the insights extracted from the interview findings. Most of the junior interviewees emphasised the influence of leaders' creativity encouragement on the team's climate for innovation. For example, an interviewed architect from firm D described: “...Here, the [design] directors are very open and always encourage us to come up with our own ideas. Especially for young architects like us, we always have fresh solutions. It makes us feel more confident in putting our ideas forward. It also makes us think and try to work together to come up with the best way of doing things." In addition, from the senior interviewees' perspective, encouraging creativity among team members is perceived to be very important since innovative design, either architectural or engineering, relies heavily on team efforts that build upon an individual's creativity; as one of the principal architects from firm C reasoned: “...Design is very much a group effort. This is why we always try to encourage them to think and to make sure that everyone in the team contributes. Getting them to work together and to share ideas is very important in developing good design." Responses from the interviews also provided an indication that the way in which leaders encourage and openly welcome ideas from team members may be associated with the perception of 'trust' that leaders placed in their teams. Such trust creates a 'circle of respect' which plays a significant role in motivating members to support each other in developing innovative ideas.

\subsection{Path relationship 2}

The path model indicated that the level of support for innovation in teams (TCI4 $\rightarrow$ OCI1 and TCI4 $\rightarrow$ OCI3) has a positive influence on the propensity for creativity (i.e. flexible, risk-oriented, collaborative environment) and innovation support and facilitation (i.e. provide enough resources, training, etc.). In support of these links, the interviewed engineers from firm A believed that the current creative, 'think 
beyond the square', culture of their firm is essentially reliant upon its innovative people and the way they collaborate. One of the junior engineers described: “...We have a lot of brilliant people who are very open-minded and are willing to help each other. I think that this is the key to our innovative culture." This relationship is further elaborated by an opinion from one of the interviewees from firm $\mathrm{C}$ who perceived that an innovation-conducive culture must be 'inclusive' because creating innovative design requires a high level of collaboration. He reasoned that if communication channels become more 'hierarchical', the quality of the supportive relationships underpinning the process of idea generation and development among teams will deteriorate. This will, in turn, adversely affect the culture of the firm as a whole. To achieve such an inclusive culture, he further emphasised that leaders must constantly encourage people to think about and contribute new ideas. This comment further supports the findings discussed in the preceding section. Additionally, a comment from the senior engineer from firm A confirmed the relationship between the climate for innovation in teams and the level of innovation support provided by the firm; as he briefly explained: “...If they [team members] show their enthusiasm and willingness to learn new things, our firm will usually provide full support to them." The support provided by the firm was said to be in the form of training and development programs (either internal or external), free time for employees to research new ideas, to name a few. Evidently, it can be inferred that the more strongly the team demonstrates the potential to innovate, the higher the level of support provided by the firm.

\subsection{Path relationship 3}

Outcomes of innovation diffusion are a direct result of either bottom-up or top-down diffusion mechanisms [29]. The former generally represents the generation of innovative ideas, solutions or products whereas the latter refers to the adoption of new ideas, technologies or methods. As a result, an effective bottom-up diffusion process should yield innovative design solutions, and a successful top-down diffusion mechanism should result in innovative design practices. The path model clearly indicated two critical links for further investigation in the interviews: a firm's propensity for creativity can determine the degree of innovativeness of the design solutions (OCI1 $\rightarrow$ IDO1); and the level of a firm's innovation 
support and facilitation has an influence on the utilisation of innovative design practices (OCI3 $\rightarrow$ IDO2). The former was supported by most of the interviewees, particularly those from firm A and E, who believed that by having a culture that is suitable for creativity (i.e. flexible, adaptive, highly collaborative and risk-oriented), their firms consistently deliver innovative design products because creative ideas generated by teams are likely to be seriously considered, adopted and finally translated into innovative outcomes. Similarly, the latter link was also corroborated as the interview participants strongly agreed that new design practices/concepts can be quickly adopted and diffused if the firm provides sufficient training and on-going technical support. In addition, the engineering manager from firm B realised the potential benefits of being innovative. He recently championed a management restructure, which he believed has helped transform the firm's culture into one that is more flexible, supportive and more inclined to use innovative approaches in carrying out projects. With this improved culture, he believed that the firm is employing more innovative practices, and is likely to deliver better innovative outcomes.

\subsection{Path relationship 4}

Client satisfaction was found to be the critical business performance factor that results from effective innovation diffusion, in the context of the developed path model (IDO1 $\rightarrow$ BPM2 and IDO2 $\rightarrow$ BPM2). According to one of the senior interviewees, achieving client satisfaction is imperative since the current and future business prospects of design (and other service-intensive) firms are highly dependent upon the extent to which clients are impressed with design solutions and how this translates into a profitable investment. To achieve a high level of client satisfaction, the path model suggested that high levels of innovative design solutions and innovative design practices must be achieved. The interviewed senior engineer from firm A provided a comment that supports these relationships. He emphasised that innovation has always been a core value of the firm because it provides a 'competitive advantage' and makes the firm 'unique'. He further explained that most clients were impressed by the firm's innovative approaches to design because they often helped to reduce long-term costs. He also admitted that sometimes innovative solutions incurred higher design fees, requiring the ability to persuade clients to look beyond the up-front costs in order to understand longer term benefits. Another interviewee 
confirmed this insight, by stating that the key is to conduct extensive research on best practice design approaches and ensure that clients are engaged in every step of the design project. This also involves the use of such innovative practices as value management and life cycle costing, which are essential in keeping clients informed so that they can discern the value that innovation adds to their project. Most of the other interviewees from the remaining firms also provided similar accounts that reinforce the above links.

\section{Concluding remarks}

This paper presents a study that sought to improve upon the current level of understanding on innovation diffusion within the AED firm context. Using an outcome from a prior empirical study as a research input, the present study employed a series of quantitative and qualitative analyses to pinpoint definitive pathways and practical strategies for deriving outcomes from innovation. Specifically, the findings resulting from the research approach presented herein revealed critical insights into the specific mechanisms for enhancing innovation diffusion outcomes and business performance in AED firms. These findings are summarised below.

Firstly, it was found that creativity stimulation and inspiration is a critical leadership trait that strongly influences the level of innovation support in teams. This can be achieved by actively encouraging and challenging team members to develop and contribute their ideas. In the transformational leadership theory's term, such behaviour is known as 'intellectual stimulation' [30,31]. According to De Jong et. al. [32], intellectual stimulation increases team members' awareness of problems and ignites rethinking of old ways of doing things. Under this situation, members are expected to make more suggestions and contributions. As a result, when creativity is encouraged and challenged, team members are more likely to contribute and collaborate in order to generate ideas. In addition, 'trust' has also been found to be another factor that might fuel innovation support among team members. This additional finding is consistent with the results of a study completed by Podsakoff et al. [33] which concluded that transformational leadership approaches can lead to the development of trust, which can, in turn, improve the way team members 
collaborate and support one another. Overall, the finding underlies the key role of creativity-conducive leaders in improving the support for innovation among teams

Secondly, the study found that the level of team support for innovation plays a vital role in determining a firm's culture for innovation, which is indicated by the level of the firm's propensity for creativity and the extent to which the firm supports and facilitates innovation efforts. This implies that if a firm has a critical mass of teams comprising members who actively support each other in developing innovative ideas, the firm's culture tends to be shaped in such a way that it fits the teams' innovative behaviour. This is particularly true when considering that an organisation is a function of the people behaving within it [34]. As such, this finding highlights the significance of creating innovation-supportive teams as they are a fundamental building block of a firm's creative and supportive culture. This also confirms an important role that creative people play in shaping an organisation's culture that favours innovation [7].

Thirdly, the study revealed that a firm's propensity for creativity will significantly contribute to the ability to deliver more innovative design solutions. Firms with proclivity for creativity tend to posses a culture in which there is a strong presence of flexibility, open collaboration, creativity encouragement and risk tolerance $[8,35]$. Within such a culture, creative ideas are more likely to be conceived and transformed into innovative products. The finding also suggested that improving a firm's innovation support and facilitation will enhance the level of innovative design practices. As innovative practices are usually in the form of top-down innovations being adopted within a firm, sufficient support such as training, technical assistance, etc. will significantly help facilitate the adoption and diffusion of such practices. For these reasons, to succeed in diffusing bottom-up and/or top-down innovations, firms should work hard to ensure that both cultural traits prevail.

Lastly, innovative design solutions and practices were found to be important determinants of client satisfaction, which is a critical indicator of business performance. The result implied that both innovative design solutions and practices must be jointly achieved in order to attain a high level of client satisfaction. This is essentially because the intrinsic value of most innovative design solutions cannot be easily 
perceived by the client; and AED firms thus require innovative design practices to help unveil the degree of value added. Once the value of innovation has been made explicit, the client will be able to appreciate the immense benefits that innovative design solutions can bring about. In this way, the client will be more likely to gain satisfaction from the design products and the quality of the service rendered by the firm. Therefore, in order to enhance the business performance, it is suggested that AED firms should place an emphasis on keeping a high level of client satisfaction, which can be achieved through consistently delivering innovative design practices and solutions.

In summary, the findings and discussion presented in this research paper provide definitive strategic guidance for AED firms seeking to diagnose and improve their existing innovation capability which could, in turn, strengthen their business performance.

\section{Future research}

It is important to note that the innovation process philosophy (e.g. Rogers' DOI theory) which formed the basis of the research model was grounded in the 'rational' school of thought, viewing innovation as a linear, multi-stage process. Despite having a dominant role in many innovation studies, it has been acknowledged that the rational approach does not fully capture the process of movement, interaction and feedback of knowledge and resource, which exist in the dynamic environment of an organisation [36]. Therefore, future research should have the benefit of applying a system thinking approach, namely 'system dynamic modelling', to re-examine the model developed in this study. By using this technique, the model would be able to better portray the process of interaction and feedback among the model factors, thus better addressing the real-time dynamics of innovation processes and organisational reality. In addition, future research may adopt the herein developed model to conduct a comparative analysis between AED firms operating in Australia and those in other countries. The results may shed additional light on how the cultural differences affect the climate for innovation as well as its innovation-related outcomes. 


\section{References}

[1] E.M. Rogers, Diffusion of Innovations, 5th ed., Free Press, New York, 2003.

[2] P.G. Bain, L. Mann, A. Pirola-Merlo, The Innovation imperative: the relationships between team climate, innovation, and performance in research and development teams, Small Group Research 32 (1) (2001) 55-73.

[3] I. Dackert, L. Loov, M. Martensson, Leadership and climate for innovation in teams, Economic and Industrial Democracy 25 (2) (2004) 301-318.

[4] G. Zaltman, R. Duncan, J. Holbek, Innovations and Organizations, Wiley, New York, 1973.

[5] R.M. Kanter, When a thousand flowers bloom: structural, collective and social conditions for innovation in organization, Research in Organizational Behavior 10 (1988) 169-212.

[6] M.A. West, The social psychology of innovation in groups, in: M.A. West, J.L. Farr (Eds.), Innovation and Creativity at Work, John Wiley \& Sons, Chichester, 1990, pp. 309-333.

[7] P.K. Ahmed, Culture and climate for innovation, European Journal of Innovation Management 1 (1) (1998) 30-43.

[8] G. Ekvall, Organizational climate for creativity and innovation, European Journal of Work and Organizational Psychology 5 (1) (1996) 105-123.

[9] P.K. Wong, Z.L. He, The moderating effect of a firm's internal climate for innovation on the impact of public R\&D support programmes, International Journal of Entrepreneurship and Innovation Management 3 (5-6) (2003) 525-545.

[10] M. Sexton, P. Barrett, A literature synthesis of innovation in small construction firms: insights, ambiguities and questions, Construction Management and Economics 21 (6) (2003) 613-622.

[11] D. Eaton, R. Akbiyikli, M. Dickinson, An evaluation of the stimulants and impediments to innovation within PFI/PPP projects, Construction Innovation 6 (2) (2006) 63-77.

[12] C.O. Egbu, J. Henry, G.R. Kaye, P. Quintas, T.R. Schumacher, B.A. Young, Managing organizational innovations in construction, in: W. Hughes (Ed.), Proceedings of the 14th Annual Conference of the Association of Researchers in Construction Management (ARCOM), Reading, 1998, pp. 605-614.

[13] P. Mitropoulos, C.B. Tatum, Technology adoption decisions in construction organizations, Journal of Construction Engineering and Management 125 (5) (1999) 330-338.

[14] R.A. Stewart, S. Mohamed, M. Marosszeky, An empirical investigation into the link between information technology implementation barriers and coping strategies in the Australian construction industry, Construction Innovation 4 (3) (2004) 155-171.

[15] V. Peansupap, D. Walker, Exploratory factors influencing information and communication technology diffusion and adoption within Australian construction organizations: a micro analysis, Construction Innovation 5 (3) (2005) 135-157. 
[16] K. Panuwatwanich, R.A. Stewart, S. Mohamed, The role of climate for innovation in enhancing business performance: the case of design firms, Engineering, Construction and Architectural Management 15 (5) (2008) 407-422.

[17] J.P. Lundblad, A Review and Critique of Rogers' Diffusion of Innovation Theory as it Applies to Organizations, Organization Development Journal 21 (4) (2003) 50-64.

[18] K. Lyytinen, J. Damsgaard, What's wrong with the diffusion of innovation theory?, in: B.L. Marcolin (Ed.), Proceedings of IFIP TC8 WG8.6 Fourth Working Conference on Diffusing Software Product and Process Innovations Springer, Banff, Canada, 2001, pp. 173-190.

[19] P.E.D. Love, G.D. Holt, H. Li, Triangulation in construction management research, Engineering, Construction and Architectural Management 9 (4) (2002) 294-303.

[20] C.K. Wing, J. Rafferty, A. Walker, The baby and the bathwater: research methods in construction management, Construction Management and Economics 16 (1) (1998) 105-108.

[21] A. Tashakkori, C. Teddlie, Mixed Methodology: Combining Qualitative and Quantitative Approaches, SAGE Publications, Thousand Oaks, 1998.

[22] J. Cohen, Statistical Power Analysis for the Behavioral Sciences, 2nd ed., L. Erlbaum Associates, Hillsdale, N.J., 1988.

[23] R.B. Kline, Principles and Practice of Structural Equation Modeling, 2nd ed., Guilford Press, New York, 2005.

[24] G.M. Maruyama, Basics of Structural Equation Modeling, Sage Publications, Thousand Oaks, 1998.

[25] J.F. Hair, W.C. Black, B.J. Babin, R.E. Anderson, R.L. Tatham, Multivariate Data Analysis, 6th ed., Pearson Prentice Hall, Upper Saddle River, N.J., 2006.

[26] W.W. Chin, Issues and opinion on structural equation modeling, MIS Quarterly 22 (1) (1998) viixvi.

[27] G.J. Nicholson, G.C. Kiel, Can directors impact performance? A case-based test of three theories of corporate governance, Corporate Governance 15 (4) (2007) 585-608.

[28] M.B. Miles, A.M. Huberman, Qualitative Data Analysis: An Expanded Sourcebook, 2nd ed., SAGE Publications, Thousand Oaks, 1994.

[29] G. Winch, Zephyrs of creative destruction: understanding the management of innovation in construction, Building Research \& Information 26 (4) (1998) 268-279.

[30] B.M. Bass, B.J. Avolio, Improving Organizational Effectiveness through Transformational Leadership, Sage Publications, Thousand Oaks, 1994.

[31] D.I. Jung, C. Chow, A. Wu, The role of transformational leadership in enhancing organizational innovation: hypotheses and some preliminary findings, The Leadership Quarterly 14 (4-5) (2003) 525-544.

[32] J. De Jong, D. Den Hartog, Leadership as a Determinant of Innovative Behaviour: A Conceptual Framework, Scientific Analysis of Entrepreneurship and SMEs (SCALES), Zoetermeer, 2003. 
[33] P.M. Podsakoff, S.B. MacKenzie, R.H. Moorman, R. Fetter, Transformational leader behaviors and their effects on followers' trust in leader, satisfaction, and organizational citizenship behaviors, Leadership Quarterly 1 (2) (1990) 107-142.

[34] B. Schneider, The people make the place, Personnel Psychology 40 (1987) 437-453.

[35] T.M. Amabile, R. Conti, H. Coon, J. Lazenby, M. Herron, Assessing the work environment for creativity, The Academy of Management Journal 39 (5) (1996) 1154-1184.

[36] P. Barrett, M. Sexton, Innovation in small, project-based construction firms, British Journal of Management 17 (4) (2005) 331-346. 


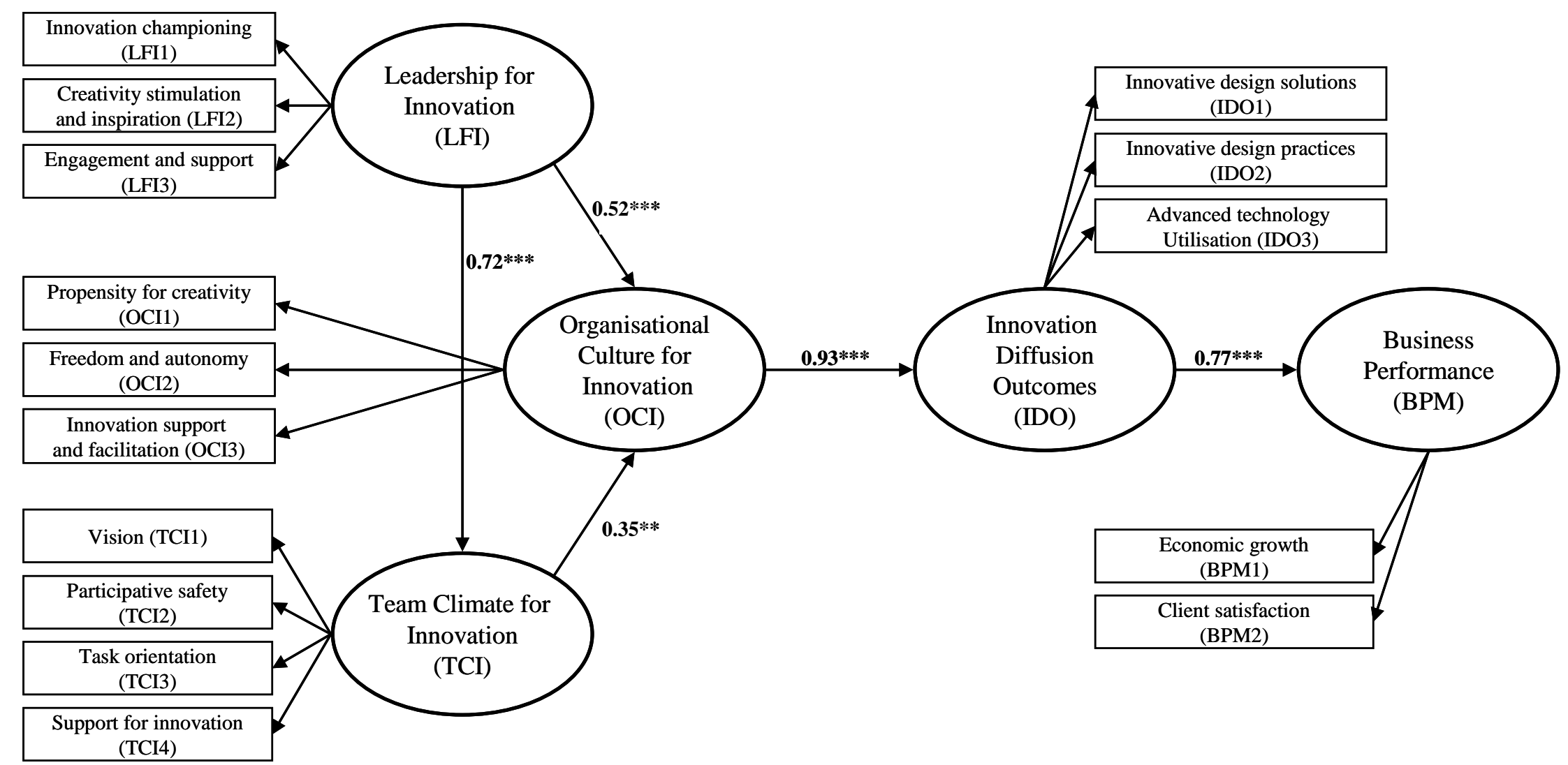

Model fit indices: $\chi^{2}=158.20 ; d f=85 ; \chi^{2} / d f=1.86 ;$ GFI $=0.89 ;$ CFI $=0.93 ;$ IFI $=0.93 ;$ RMSEA $=0.07$.

Note: ${ }^{* *} p<0.01 ; * * * p<0.001$; For clarity, error terms and variances are not shown.

Fig. 1. Research model: empirical model for innovation diffusion [16] 


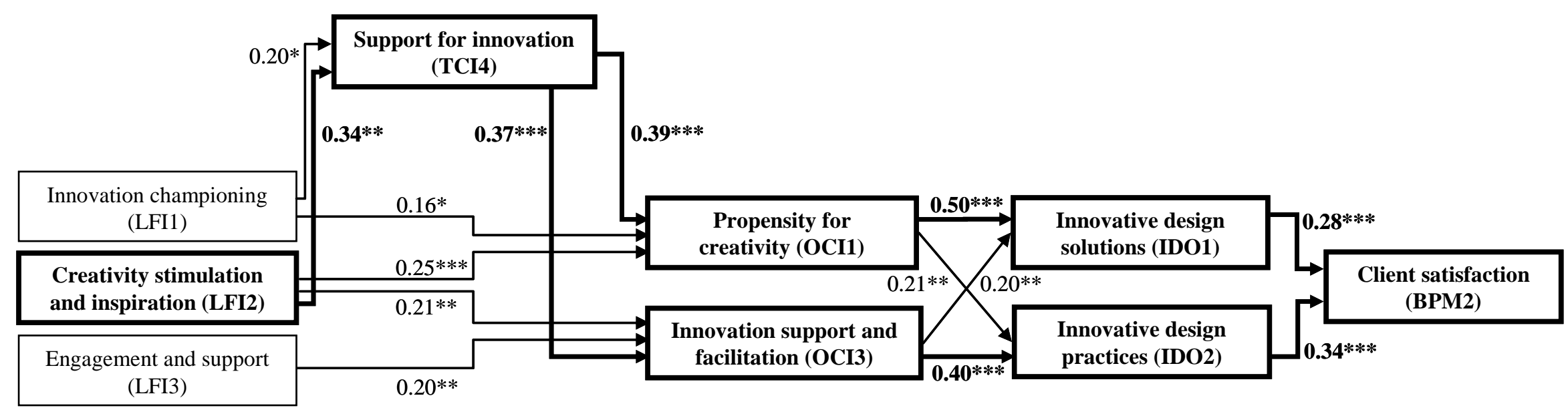

Model fit indices: $\chi^{2}=39.42 ; d f=17 ; \chi^{2} / d f=2.32 ; \mathrm{GFI}=0.96 ; \mathrm{CFI}=0.97 ; \mathrm{IFI}=0.97 ; \mathrm{RMSEA}=0.08$.

Note: $* p<0.05 ; * * p<0.01 ; * * * p<0.001$.

Critical paths (standardised coefficients greater than or around 0.30 ) and associated factors are bold.

For clarity, error variances are not shown.

Fig. 2. Path model 
Table 1 Description of research model factors

\begin{tabular}{l} 
Model Factor \\
\hline LFI1: Innovation championing \\
LFI2: Creativity stimulation and inspiration
\end{tabular}

LFI3: Engagement and support

TCI1: Vision

Description

Concerned with the degree to which leaders seek out and promote new ideas, technologies and/or innovative approaches for solving problems.

Concerned with the degree to which leaders inspire and encourage team members to develop new ideas and/or approaches for solving problems.

Concerned with the quality of supportive relationships between leaders and their subordinates.

Concerned with the establishment of a team's clearly defined and shared goal that provides focus and direction to team members as a motivating force at work.

TCI2: Participative safety

Concerned with the degree to which involvement in decision making is motivated and reinforced without fear of criticism among team members.

TCI3: Task orientation

Concerned with the degree of concern with the quality of task performance in relation to shared vision or outcomes among team members.

TCI4: Support for innovation

Concerned with the degree of expectation, approval and practical support of any attempts made by team members to introduce new and improved ways of doing things.

OCI1: Propensity for creativity

OCI2: Freedom and autonomy

Concerned with the aspect of the firm's culture that is conducive to creativity, in terms of the perceived degree of flexibility, risk orientation, and open collaboration.

Concerned with the extent to which the firm allows its members to have freedom in carrying out their own work.

OCI3: Innovation support and facilitation

Concerned with the perceived availability of resource in terms of training, manpower, time and money set aside for creative/innovative activities.

IDO1: Innovative design solutions

Concerned with the level of innovativeness of the firm's design solutions (e.g. awards, industry recognition, etc.).

IDO2: Innovative design practices

Concerned with the extent to which innovative (value-based) design practices are utilised to facilitate design processes (e.g. value management, constructability review, life cycle costing, etc.).

IDO3: Advanced technology utilisation

Concerned with the level of design technology utilised to facilitate design activities (e.g. design representation, utilisation of advanced software tools, etc.).

BPM1: Economic growth

Concerned with the firm's level of growth in terms of turnover, profitability and market share.

Concerned with the extent to which clients are satisfied with the firm's design solutions and services provided. 


\begin{tabular}{|c|c|c|c|c|c|c|c|c|c|c|c|c|c|c|c|}
\hline \multirow[b]{2}{*}{$\begin{array}{l}\text { Dependent } \\
\text { Factors }\end{array}$} & \multicolumn{15}{|c|}{ Independent Factors } \\
\hline & $\underline{\text { LFI1 }}$ & $\underline{\text { LFI2 }}$ & $\underline{\text { LFI3 }}$ & TCI1 & TCI2 & TCI3 & $\underline{\text { TCI4 }}$ & $\underline{\text { OCI1 }}$ & OCI2 & $\underline{\text { OCI3 }}$ & IDO1 & $\underline{\text { IDO2 }}$ & IDO3 & BPM1 & BPM2 \\
\hline LFI1 & 1 & & & & & & & & & & & & & & \\
\hline LFI2 & $0.53^{* *}$ & 1 & & & & & & & & & & & & & \\
\hline LFI3 & $0.45^{* *}$ & $0.64 * *$ & 1 & & & & & & & & & & & & \\
\hline TCI1 & $0.35^{* *}$ & $0.41 * *$ & $0.45^{* *}$ & 1 & & & & & & & & & & & \\
\hline TCI2 & $0.33 * *$ & $0.41 * *$ & $0.49 * *$ & $0.56^{* *}$ & 1 & & & & & & & & & & \\
\hline TCI3 & $0.27 * *$ & $0.34 * *$ & $0.39 * *$ & $0.48 * *$ & $0.56^{* *}$ & 1 & & & & & & & & & \\
\hline TCI4 & $0.36^{* *}$ & $0.44 * *$ & $0.38 * *$ & $0.49 * *$ & $0.50 * *$ & $0.53 * *$ & 1 & & & & & & & & \\
\hline$\underline{\text { OCI1 }}$ & $0.47 * *$ & $0.50 * *$ & $0.35 * *$ & $0.42 * *$ & $0.30 * *$ & $0.36 * *$ & $0.55 * *$ & 1 & & & & & & & \\
\hline OCI2 & $0.33 * *$ & $0.35 * *$ & $0.37 * *$ & $0.29 * *$ & $0.25 * *$ & $0.29 * *$ & $0.29 * *$ & $0.44 * *$ & 1 & & & & & & \\
\hline$\underline{\mathrm{OCI} 3}$ & $0.43^{* *}$ & $0.50 * *$ & $0.46^{* *}$ & $0.39 * *$ & $0.28 * *$ & $0.32 * *$ & $0.54 * *$ & $0.62 * *$ & $0.42 * *$ & 1 & & & & & \\
\hline IDO1 & $0.36^{* *}$ & $0.40 * *$ & $0.29 * *$ & $0.31 * *$ & $0.30 * *$ & $0.26 * *$ & $0.47 * *$ & $0.63 * *$ & $0.30 * *$ & $0.51 * *$ & 1 & & & & \\
\hline IDO2 & $0.39 * *$ & $0.38 * *$ & $0.38 * *$ & $0.32 * *$ & $0.20 * *$ & $0.37 * *$ & $0.47 * *$ & $0.46^{* *}$ & $0.24 * *$ & $0.53 * *$ & $0.45^{* *}$ & 1 & & & \\
\hline IDO3 & $0.18^{* *}$ & $0.20 * *$ & $0.14^{*}$ & 0.06 & 0.06 & -0.02 & $0.20^{* *}$ & $0.22 * *$ & -0.01 & $0.25 * *$ & $0.23^{* *}$ & $0.23 * *$ & 1 & & \\
\hline BPM1 & $0.30^{* *}$ & $0.30^{* *}$ & $0.23^{* *}$ & $0.36^{* *}$ & $0.23 * *$ & $0.20 * *$ & $0.29 * *$ & $0.37 * *$ & $0.13^{*}$ & $0.39 * *$ & $0.41^{* *}$ & $0.43 * *$ & $0.20 * *$ & 1 & \\
\hline BPM2 & $0.37 * *$ & $0.42 * *$ & $0.41^{* *}$ & $0.51 * *$ & $0.36^{* *}$ & $0.32 * *$ & $0.35^{* *}$ & $0.41 * *$ & $0.27 * *$ & $0.47 * *$ & $0.43^{* *}$ & $0.47 * *$ & 0.09 & $0.59 * *$ & 1 \\
\hline
\end{tabular}

$n=181 ; * p<0.05$ (one-tailed); $* * p<0.01$ (one-tailed).
Correlation coefficients greater than or close to 0.50 are bold and their corresponding factors underlined. 
Table 3 Profiles of interview participants

\begin{tabular}{|c|c|c|c|c|c|}
\hline Firm & $\begin{array}{l}\text { No. of } \\
\text { employees }\end{array}$ & Areas of expertise & Scope & Interview participants (duration) & Interview location \\
\hline Firm A & $\sim 360$ & $\begin{array}{l}\text { Civil and structural engineering, } \\
\text { infrastructure planning, value } \\
\text { engineering }\end{array}$ & $\begin{array}{l}\text { International } \\
\text { (8 offices: } 6 \text { in } \\
\text { Australia; } 2 \\
\text { overseas) }\end{array}$ & $\begin{array}{l}\text { - } 1 \text { senior structural engineer (45 mins) } \\
\text { - } 2 \text { junior structural engineers (60 and } 40 \text { mins) } \\
\text { - } 1 \text { structural drafting manager (20 mins) }\end{array}$ & Gold Coast office \\
\hline Firm B & $\sim 100$ & $\begin{array}{l}\text { Civil and structural engineering, } \\
\text { surveyors, geosciences }\end{array}$ & $\begin{array}{l}\text { Regional } \\
\text { (3 offices, all in } \\
\text { Queensland) }\end{array}$ & $\begin{array}{l}\text { - } 1 \text { engineering manager (50 mins) } \\
\text { - } 1 \text { senior structural engineer (40 mins) } \\
\text { - } 1 \text { junior structural draftsperson (40 mins) } \\
\text { - } 1 \text { senior structural draftsperson (45 mins) }\end{array}$ & Brisbane office \\
\hline Firm C & $\sim 250$ & $\begin{array}{l}\text { Architectural and interior design, } \\
\text { urban design and planning }\end{array}$ & $\begin{array}{l}\text { National } \\
\text { (4 offices in four } \\
\text { states) }\end{array}$ & $\begin{array}{l}\text { - } 1 \text { principal architect ( } 30 \text { mins) } \\
\text { - } 1 \text { senior architect (45 mins) } \\
\text { - } 2 \text { junior architects (45 and } 20 \text { mins) }\end{array}$ & Brisbane office \\
\hline Firm D & $\sim 100$ & $\begin{array}{l}\text { Architectural design and planning, } \\
\text { building refurbishment, interior } \\
\text { design, facilities planning }\end{array}$ & $\begin{array}{l}\text { International } \\
\text { (5 offices: } 3 \text { in } \\
\text { Australia; } 2 \\
\text { overseas) }\end{array}$ & $\begin{array}{l}\text { - } 1 \text { design associate ( } 30 \text { mins }) \\
\text { - } 1 \text { senior architect (50 mins) } \\
\text { - } 2 \text { junior architectural technicians (30 mins each) }\end{array}$ & Brisbane office \\
\hline Firm E & $\sim 210$ & $\begin{array}{l}\text { Architecture, interior architecture, } \\
\text { urban design and planning }\end{array}$ & $\begin{array}{l}\text { International } \\
\text { (5 offices: } 3 \text { in } \\
\text { Australia; } 2 \\
\text { overseas) }\end{array}$ & $\begin{array}{l}\text { - } 1 \text { design director (40 mins) } \\
\text { - } 1 \text { junior architect }(35 \text { mins }) \\
\text { - } 1 \text { senior interior designer (20 mins) }\end{array}$ & Brisbane office \\
\hline
\end{tabular}

